Journal of Biotechnology and Strategic Health Research

Araştırma Makalesi / Research Article

http://dergipark.org.tr/tr/pub/bshr

\title{
Perfüzyonist Mesleğinin Sağlık Çalışanları Arasındaki Bilinirliği
}

\section{Awareness of Perfusionist Profession Among Healthcare Professionals}

\author{
(i) Bişar Amaç ${ }^{1}$, (D) Ecehan Baltaci²
}

${ }^{1}$ Sağlık Bilimleri Üniversitesi, Şanlıurfa Mehmet Akif İnan Eğitim ve Araştırma Hastanesi, Perfüzyon Bölümü, Şanlıurfa, Türkiye

${ }^{2}$ Şanlıurfa Eğitim ve Araştırma Hastanesi, Perfüzyon Bölümü, Şanlıurfa, Türkiye

ORCID ID: Bişar Amaç 0000-0003-0320-4239, Ecehan Baltacı 0000-0001-6834-4617

*Sorumlu Yazar / Corresponding Author: Perf. Bişar Amaç, e-posta / e-mail: amacbisar@gmail.com4

Geliş Tarihi / Received : 11-03-2020 Kabul Tarihi / Accepted: 25-04-2020 Yayın Tarihi / Online Published: 30-04-2020

Atıf Gösterimi/How to Cite: Amaç B., Baltacı E. Perfüzyonist Mesleğinin Sağlık Çalışanları Arasındaki Bilinirliği, J Biotechnol and

Strategic Health Res. 2020;4(1):33-38

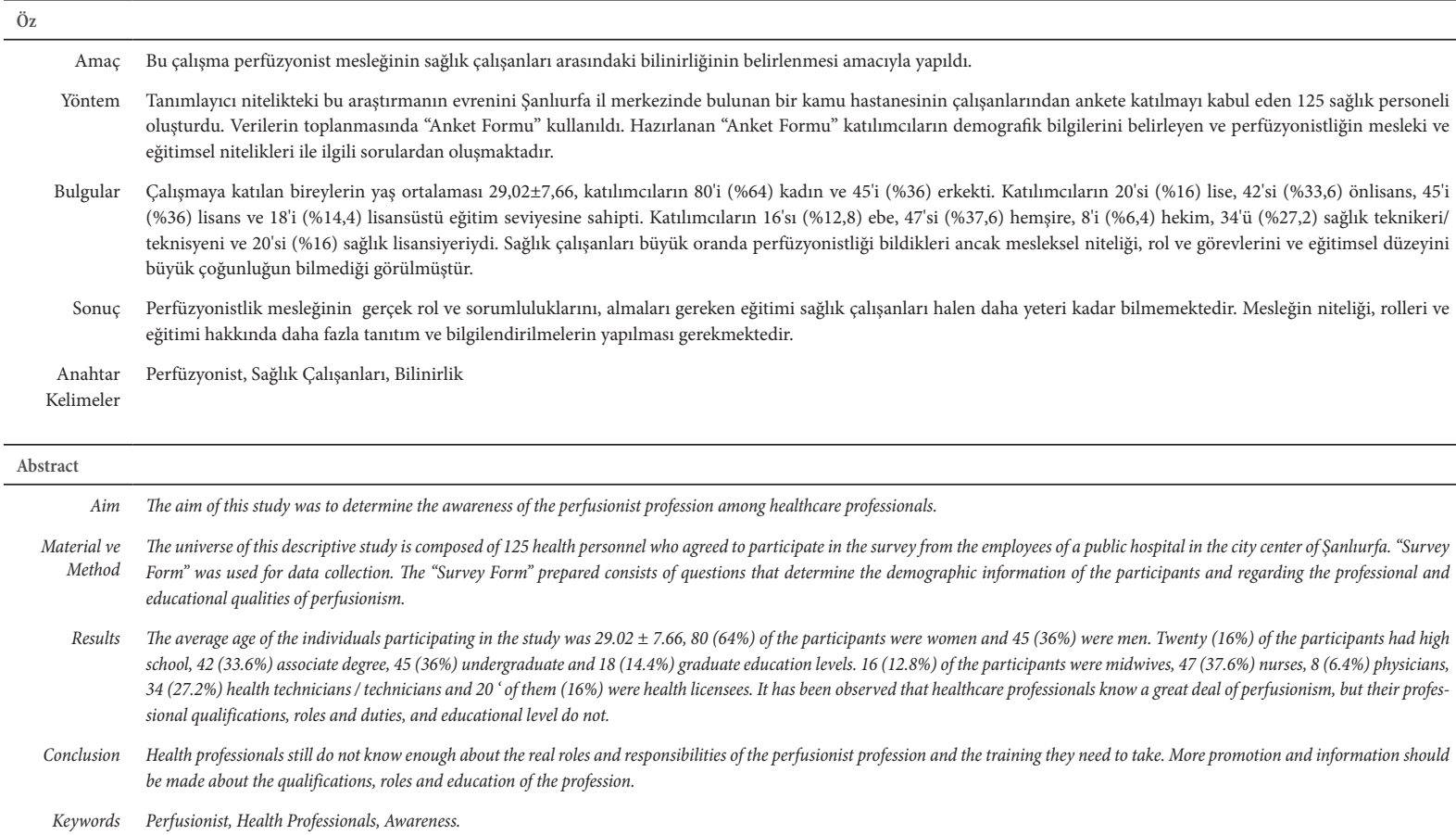

Yöntem Tanımlayıcı nitelikteki bu araştırmanın evrenini Şanlıurfa il merkezinde bulunan bir kamu hastanesinin çalışanlarından ankete katılmayı kabul eden 125 sağlık personeli oluşturdu. Verilerin toplanmasında "Anket Formu” kullanıld. Hazırlanan "Anket Formu” katılımcıların demografik bilgilerini belirleyen ve perfüzyonistliğin mesleki ve eğitimsel nitelikleri ile ilgili sorulardan oluşmaktadır.

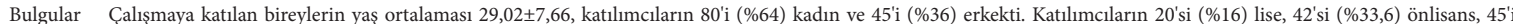
(\%36) lisans ve 18'i (\%14,4) lisansüstü eğitim seviyesine sahipti. Katılımclların 16'sı (\%12,8) ebe, 47'si (\%37,6) hemşire, 8'i (\%6,4) hekim, 34'ü (\%27,2) sağlık teknikeri/ teknisyeni ve 20'si (\%16) sağlı lisansiyeriydi. Sağlık çalışanları büyük oranda perfüzyonistliği bildikleri ancak mesleksel niteliği, rol ve görevlerini ve eğitimsel düzeyini büyük çoğunluğun bilmediği görülmüştür.

Sonuç Perfüzyonistlik mesleğinin gerçek rol ve sorumluluklarını, almaları gereken eğitimi sağlık çalışanları halen daha yeteri kadar bilmemektedir. Mesleğin niteliği, rolleri ve eğitimi hakkında daha fazla tanıtım ve bilgilendirilmelerin yapılması gerekmektedir.

Anahtar Perfüzyonist, Sağlık Calıșanları, Bilinirlik

Kelimeler

Abstract

Aim The aim of this study was to determine the awareness of the perfusionist profession among healthcare professionals.

Material ve The universe of this descriptive study is composed of 125 health personnel who agreed to participate in the survey from the employees of a public hospital in the city center of Sanlurfa. "Survey

Method Form" was used for data collection. The "Survey Form" prepared consists of questions that determine the demographic information of the participants and regarding the professional and educational qualities of perfusionism.

Results The average age of the individuals participating in the study was $29.02 \pm 7.66,80$ (64\%) of the participants were women and 45 (36\%) were men. Twenty (16\%) of the participants had high school, $42(33.6 \%)$ associate degree, $45(36 \%)$ undergraduate and 18 (14.4\%) graduate education levels. $16(12.8 \%)$ of the participants were midwives, $47(37.6 \%)$ nurses, $8(6.4 \%)$ physicians, $34(27.2 \%)$ health technicians / technicians and $20^{\circ}$ of them (16\%) were health licensees. It has been observed that healthcare professionals know a great deal of perfusionism, but their professional qualifications, roles and duties, and educational level do not.

Conclusion Health professionals still do not know enough about the real roles and responsibilities of the perfusionist profession and the training they need to take. More promotion and information should be made about the qualifications, roles and education of the profession.

Keywords Perfusionist, Health Professionals, Awareness. 


\section{GIIRIŞ}

Modern kalp cerrahisindeki en önemli olay ekstrakorporeal dolaşım tekniğinin kullanılmasıdır. Kalp cerrahisindeki diğer en önemli olay ise heparinin klinikte kullanılmasıdır. Heparin Mc. Lean tarafından keşfedilmiştir. 1930'lu yıllarda klinikte kullanılmaya başlanmıştır. O yıllarda Olson ve Chargoff tarafindan da heparinin etkisinin protamin ile nötralize edildiği keşfedilmiştir. John Gibbon dünya da ilk kez ekstrakorporeal dolaşım tekniği ile açık kalp cerrahisi ameliyatını başarılı bir şekilde yapmıştır. Ülkemizde ekstrakorporeal dolaşım tekniği kullanılarak yapılan ilk açık kalp cerrahisi ameliyatı 1960 yılında Dr. Mehmet Tekdoğan tarafından Hacettepe Üniversitesinde yapılmıştır. Seri halindeki ilk açık kalp cerrahisi ameliyatlarını ise Dr. Aydın Aytaç 1962'de Hacettepe Çocuk Hastalıkları Hastanesinde yapmıştır. ${ }^{1}$

Amerika'da ve Avrupa ülkelerinde perfüzyonist meslek tanımı farklılık gösterse de genel olarak şu şekildedir: Ekstrakorporeal dolaşım gerektiren kalp ve büyük damarlarda yapılacak cerrahi işlemlerde ilgili uzmanlarla işbirliği içinde, kalp ve akciğerlerin fonksiyonlarını izole edip ekstrakorporeal dolaşım sistemini kullanarak perfüzyon görevini üstlenen kişi olarak tanımlanmıştır. ${ }^{2}$ Profesyonel bir klinik perfüzyonisti ise, hastaya ekstrakorporeal dolaşım hizmeti sunan, klinik ve akademik eğitim almış nitelikli kişi olarak ifade etmektedir. ${ }^{3}$

Perfüzyonist vücut dışı dolaşımın ve hastanın fizyolojik durumunun yönetiminden sorumlu profesyonel bir sağlık lisansiyeridir. Perfüzyonistlik meslek tanımı Türkiye'de henüz çok yenidir.

Türkiye'deki yasalarda perfüzyonistliğin tanımı 2011 yılında yayımlanan bir kanuna göre belirlenmiștir. Yasaya göre perfüzyonist olabilmek için perfüzyon alanında lisans veya yüksek lisans eğitimi almak gerekmektedir. Yasada ayrıca meslek tanımı: Kalp ve büyük damar cerrahisi gerektiren cerrahi operasyonlarda vücut dışı dolaşımın sağlanması için kalp ve akciğer makinesini yöneten sağlık meslek mensubu olarak tanımlanmaktadır. ${ }^{4}$ Perfüzyonistliğin görevlerini ise sağlık bakanlığının 2014 yılında yayınlamış olduğu; sağlık bakanlığı sağlık meslek mensupları ile sağlık hizmetlerinde çalışan diğer meslek mensuplarının iş ve görev tanımlarına dair yönetmelikte belirtmiştir. ${ }^{5}$

Perfüzyonistin görev, yetki ve sorumlulukları aşağıdaki şekilde belirtilebilir:

- Kalp-akciğer makinesi ve ekstrakorporeal dolaşım ekipmanını yönetmek,

- Kardiyopulmoner bypass ve ekstrakorporeal dolaşım sırasında; hastanın fizyolojik parametrelerini ve antikoagülasyonunu takip etmek, değerlendirmek ve gerekli girişimlerde bulunmak, hemofiltrasyon-ultrafiltrasyon işlemini yapmak, vücut sıcaklığını düzenlenmek, kan ürünleri transfüzyonu, medikal ve anestezik ajanların uygulamasını yapmak, miyokardın korunmasını (kardiyopleji uygulaması) sağlamaktır,

- Ayrıca ototransfüzyon, cell saver uygulaması ve izole organ-ekstremite perfüzyonunun yapılmasını sağlar6.

Bu çalışma perfüzyonist mesleğinin sağlık çalışanları arasındaki bilinirliğinin belirlenmesi amacıyla yapıldı.

\section{YÖNTEM}

Tanımlayıcı nitelikteki bu araştırmanın evrenini 01.01.2019-01.01.2020 tarihleri arasında Şanlıurfa il merkezinde bulunan bir kamu hastanesindeki çalışanlardan ankete katılmayı kabul eden 125 sağlık personeli oluşturmaktadır. Verilerin toplanmasında "Anket Formu" kullanildi.

Verilerin değerlendirilmesinde SPSS ${ }^{\circledast} 16.0$ bilgisayar programı kullanılarak gerçekleştirilmiştir. Verilerin değerlendirilmesinde sayı ve yüzdelik hesaplamaları kullanılmıştır. $\mathrm{Bu}$ araştırma Helsinki Deklarasyonu'nda (Version: B.10.4.ISM.4.06.68.48/184) belirtilen ilkelere uyularak yürütüldü. Araştırmaya katılan bireylerden ise araştırmanın amacı açıklanarak sözlü onam alınmıştır. 
Hazırlanan "Anket Formu” katılımcıların yaş, cinsiyet, eğitim seviyesi ve mesleki bilgilerini belirleyen ve perfüzyonistliğin mesleki ve eğitimsel nitelikleri ile ilgili sorulardan oluşmaktadır (Tablo 1).

\begin{tabular}{|l|}
\hline Tablo 1. Anket Soruları \\
\hline 1. Perfüzyon kelimesini daha önce duydunuz mu? \\
Evet $\square \quad$ Hayır $\square$ \\
\hline 2. Perfüzyonist mesleğini biliyor musunuz? \\
Evet $\square \quad$ Hayır $\square$ \\
\hline 3. Perfüzyonist nerede çalışır? \\
(Lütfen tek bir yanıt veriniz) \\
a- Yataklı Servisler \\
b- Görüntüleme Birimi \\
c- Laboratuar Birimi \\
d- Poliklinik Birimi \\
e- Anestezi Birimi \\
f- Açık Kalp Cerrahisi Birimi \\
\hline 4. Perfüzyonist ne iş yapar? \\
(Birden çok seçeneği seçebilirsiniz) \\
a- Kardiyopulmoner bypass ameliyatlarında görev alır \\
b- Kalp-akciğer makinesinin yönetiminden sorumludur \\
c- Beyin cerrahisi ameliyatlarında görev alır \\
d- Extrakorporeal dolaşım cihazının yönetiminden sorumludur \\
e- İzole ekstremite perfüzyonunun yönetiminden sorumludur \\
f- Açık kalp cerrahisi ameliyatlarında kalbin durdurulup tekrar \\
çalıstırılmasından sorumludur \\
g- Koroner anjiyografi işleminde görev alır \\
h- Miyokard perfüzyon sintigrafisi işleminde görev alır \\
\hline 5. Perfüzyonistler hangi düzeyde eğitim alır? \\
(Lütfen tek bir yanıt veriniz) \\
a-Lisans veya yüksek lisans eğitimi \\
b-Önlisans eğitimi \\
c-Sağllk meslek lisesi eğitimi \\
d-Sertifikasyon eğitimi \\
e-Belirli bir eğitimi yoktur görevlendirme şeklinde olunur \\
\hline 6. Aşağıdakiler den hangisi veya hangileri sizce doğrudur? \\
(Birden çok seçeneği seçebilirsiniz) \\
a- Türkiye'de perfüzyonist meslek yasası vardır \\
b- Türkiye'de perfüzyonistlerin dernek vb. kurumları vardır \\
c- Perfüzyonistlik profesyonel bir sağlık mesleğidir \\
d- Perfüzyonistlik ile perfüzyon teknikerliği aynı meslektir \\
e- Çalışma koşulları ağırdır \\
f- Yönetici olabilirler \\
g- Eğitimci olabilirler \\
h- Bilimsel araştırma yapabilirler \\
\hline
\end{tabular}

\section{BULGULAR}

Çalışmamızda Tablo 2'de de görüldüğü gibi çalışmaya katılan bireylerin yaş ortalaması 29,02 $\pm 7,66$, katılımcıların 80'i (\%64) kadın ve 45'i (\%36) erkekti. Katılımcıların 20'si (\%16) lise, 42'si $(\% 33,6)$ önlisans, 45’i (\%36) lisans ve 18’i
$(\% 14,4)$ lisansüstü eğitim seviyesine sahipti. Katılımcıların 16 'sı $(\% 12,8)$ ebe, 47'si $(\% 37,6)$ hemşire, 8’i $(\% 6,4)$ hekim, 34 'ü $(\% 27,2)$ sağlık teknikeri/teknisyeni (Anestezi, röntgen, laboratuar, cerrahi, ameliyathane vb.) ve 20'si (\%16) sağlık lisansiyeri (Fizyoterapist, diyetisyen, çocuk gelişimcisi, biyolog, odyolog, ergoterapist vb.) meslek grubundandi.

\begin{tabular}{|l|c|}
\hline \multicolumn{2}{|l|}{ Tablo 2. Katılımcıların tanımlayıcı özellikleri } \\
\hline & $\mathrm{n}^{*}(\%)$ \\
\hline Yaş ortalaması & $29,02 \pm 7,66$ \\
\hline Cinsiyet & $80(\% 64)$ \\
\hline Kadın & $45(\% 36)$ \\
\hline Erkek & \\
\hline Eğitim Seviyesi & $20(\% 16)$ \\
\hline Lise & $42(\% 33,6)$ \\
\hline Önlisans & $45(\% 36)$ \\
\hline Lisans & $18(\% 14,4)$ \\
\hline Lisansüstü & \\
\hline Meslek & $16(\% 12,8)$ \\
\hline Ebe & $47(\% 37,6)$ \\
\hline Hemşire & $8(\% 6,4)$ \\
\hline Hekim & $34(\% 27,2)$ \\
\hline $\begin{array}{l}\text { Sağlık Teknikeri/teknisyeni(Anestezi, röntgen, } \\
\text { laboratuar, cerrahi, ameliyathane vb.) }\end{array}$ & $20(\% 16)$ \\
\hline $\begin{array}{l}\text { Sağlık Lisansiyeri (Fizyoterapist, diyetisyen, } \\
\text { çocuk gelişimcisi, biyolog, odyolog, ergotera- } \\
\text { pist vb.) }\end{array}$ & \\
\hline${ }^{*}$ Birey sayısı & \\
\hline
\end{tabular}

Tablo 3’te de görüldüğü gibi katılımcılar, perfüzyon kelimesini yüksek oranda duyduğunu $(\% 92,8)$, perfüzyonistlik mesleğini bildiklerini (\%88) ifade etmişlerdir. Perfüzyonistin nerede çalıştığıyla ilgili 3. soruya doğru cevabı veren katılımcı oranı tatmin edici düzeydedir $(\% 84,8)$. Katılımcılar perfüzyonistlerin ne iş yaptıklarıyla ilgili 4 . soruda ise kardiyopulmoner bypass ameliyatlarında görev aldıklarını büyük oranda bildikleri (\%88) ancak perfüzyonistlerin extrakorporeal dolaşım $(\% 19,2)$, izole ekstremite perfüzyon işlemleri $(\% 9,6)$ ve açı kalp cerrahisi ameliyatlarında kalbin durdurulup tekrar çalıştırılmasından sorumlu olduklarını $(\% 17,6)$ düşük oranda bildikleri gö- 
rülmüştür. Ayrıca katılımcıların \%12,8'i koroner anjiyografi işlemi ve \%6,4'ü miyokard perfüzyon sintigrafisi işleminde perfüzyonistlerin görev aldıklarını belirtmiş ancak bu işlemler perfüzyonistlerin yaptıkları görevler arasında değildir. Perfüzyonistlerin eğitim seviyesinin sorulduğu 5 . soruda \%36,8'i lisans veya yüksek lisans düzeyinde olduğunu belirtmiştir. Katılımcıların 6. sorudaki sorulara verdikleri yanıtlarda çok yüksek oranda yanlış bilgiye sahip oldukları görülmüştür.

\begin{tabular}{|l|c|}
\hline \multicolumn{2}{|l|}{ Tablo 3. Katılımcıların anket sorularına verdikleri yanıtların } \\
sayı ve oranları \\
\hline & $\mathrm{n}^{\star}(\%)$ \\
\hline $\begin{array}{l}\text { 1. Perfüzyon kelimesini daha önce duydunuz mu? } \\
\text { (Evet) }\end{array}$ & $116(\% 92,8)$ \\
\hline 2. Perfüzyonist mesleğini biliyor musunuz? (Evet) & $110(\% 88)$ \\
\hline $\begin{array}{l}\text { 3. Perfüzyonist nerede çalışı? (Tek bir yanıt ver- } \\
\text { meleri istenmiştir) }\end{array}$ & \\
\hline a- Yataklı Servisler & $0(\% 0)$ \\
\hline b- Görüntüleme Birimi & $12(\% 9,6)$ \\
\hline c- Laboratuar Birimi & $4(\% 3,2)$ \\
\hline d- Poliklinik Birimi & $3(\% 2,4)$ \\
\hline e- Anestezi Birimi & $0(\% 0)$ \\
\hline f- Açık Kalp Cerrahisi Birimi & $106(\% 84,8)$ \\
\hline $\begin{array}{l}\text { 4. Perfüzyonist ne iş yapar? (Birden çok seçenek } \\
\text { seçilmiştir) }\end{array}$ & $12(\% 9,6)$ \\
\hline $\begin{array}{l}\text { a- Kardiyopulmoner bypass ameliyatlarında görev } \\
\text { alır }\end{array}$ & $110(\% 88)$ \\
\hline $\begin{array}{l}\text { b- Kalp-akciğer makinesinin yönetiminden } \\
\text { sorumludur }\end{array}$ & $76(\% 60,8)$ \\
\hline c- Beyin cerrahisi ameliyatlarında görev alır & $0(\% 0)$ \\
\hline $\begin{array}{l}\text { d- Extrakorporeal dolaşım cihazının yönetimind- } \\
\text { en sorumludur }\end{array}$ & $24(\% 19,2)$ \\
\hline $\begin{array}{l}\text { e- İzole ekstremite perfüzyonunun yönetiminden } \\
\text { sorumludur }\end{array}$ & $16(\% 36,8)$ \\
\hline $\begin{array}{l}\text { f- Açık kalp cerrahisi ameliyatlarında kalbin dur- } \\
\text { durulup tekrar çalıstırılmasından sorumludur }\end{array}$ \\
\hline g- Koroner anjiyografi işleminde görev alır \\
\hline $\begin{array}{l}\text { h- Miyokard perfüzyon sintigrafisi işleminde } \\
\text { görev alır }\end{array}$ \\
\hline $\begin{array}{l}\text { 5. Perfüzyonistler hangi düzeyde eğitim alır? (Tek } \\
\text { bir yanıt vermeleri istenmiştir) }\end{array}$ \\
\hline a-Lisans veya yüksek lisans eğitimi & $0(\% 0)$ \\
\hline b-Önlisans eğitimi & $22,4)$ \\
\hline c-Sağlık meslek lisesi eğitimi & \\
\hline
\end{tabular}

\begin{tabular}{|l|c|}
\hline d-Sertifikasyon eğitimi & $25(\% 20)$ \\
\hline $\begin{array}{l}\text { e-Belirli bir eğitimi yoktur görevlendirme şeklinde } \\
\text { olunur }\end{array}$ & $6(\% 4,8)$ \\
\hline $\begin{array}{l}\text { 6. Aşağıdakiler den hangisi veya hangileri sizce } \\
\text { doğrudur? }\end{array}$ & \\
\hline (Birden çok seçenek seçilmiştir) & $54(\% 43,2)$ \\
\hline a- Türkiye'de perfüzyonist meslek yasası vardır & $26(\% 20,8)$ \\
\hline $\begin{array}{l}\text { b- Türkiye'de perfüzyonistlerin dernek vb kurum- } \\
\text { ları vardır }\end{array}$ & $42(\% 33,6)$ \\
\hline c- Perfüzyonistlik profesyonel bir sağlık mesleğidir & $108(\% 86,4)$ \\
\hline $\begin{array}{l}\text { d- Perfüzyonistlik ile perfüzyon teknikerliği aynı } \\
\text { meslektir }\end{array}$ & $20(\% 16)$ \\
\hline e- Çalışma koşulları ağırdır & $35(\% 28)$ \\
\hline f- Yönetici olabilirler & $28(\% 22,4)$ \\
\hline g- Eğitimci olabilirler & $12(\% 9,6)$ \\
\hline h- Bilimsel araştırma yapabilirler & \\
\hline *Birey sayısı & \\
\hline
\end{tabular}

\section{TARTIŞMA}

Türkiye'de sağlık çalışanları arasında perfüzyonist mesleği henüz bilinmemektedir yada sağlık çalışanları perfüzyonist mesleği hakkında yanlış bilgilere sahiptirler. Bilinmemesinin yada hakkında yanlış bilgilere sahip olunmasının birçok sebebi bulunmaktadır. Başta ülkemizde meslek yasasının yakın bir tarihe kadar bulunmamasıdır. Diğer bir sebep ise perfüzyonistliğin meslek yasası çıkmadan önce perfüzyonist meslek okullarının bulunmaması, daha önceleri perfüzyonistliğin meslek olarak görülmemesi diğer sağlık personelleri tarafından usta çırak ilişkisiyle yürütülmesidir.

Günümüzde bile perfüzyonist meslek yasasının ve perfüzyon okullarının bulunmasına rağmen Türkiyede halen mesleki sorunlar yaşanmaktadır. Bu sorunların başında perfüzyonistlik meslek kanunu ile ilgisi olmayan bazı önlisans eğitim seviyelerindeki programların varlığı gelmektedir.

Akçay O’nun göğüs cerrahlarıyla ilgili yaptığı bir çalışmada sağlık profesyonellerinin ve hastaların yeteri kadar göğüs cerrahisini tanımadığını belirtmiştir. $\mathrm{Bu}$ nedenle göğüs cerrahisi branşının ilgili meslek kuruluşları ve ku- 
rumlar tarafından tanıtımının yapılmasının gerektiğini belirtmiştir. $^{7}$

Özdelikara A. ve ark.'nın hemşirelik mesleğiyle ilgili yaptıkları çalışmada hemşirelik öğrencilerinin diğer sağlık dışı eğitim bölümlerine göre imajlarının daha yüksek olduğunu, ayrıca çalışmalarına katılan hemşirelik öğrencilerinin hemşirelik mesleği statüsünün yükselmesi için mesleklerinde branşlaşmanın gerektiğini belirtmişlerdir8. Perfüzyonist mesleğinde de branşlaşma olması gerekmektedir. Pediatrik perfüzyonist, erişkin perfüzyonist, ekmo perfüzyonisti gibi branşlaşmalar alanında profesyonelleşmeyi artıracağı gibi mesleki gelişime de katkı sağlayacaktır. Sabancıoğulları S. ve ark. yaptıkları çalışmada hemşirelik mesleğinin imajıyla ilgili tarihte devam eden kalıplaşmış görüşlerin olduğunu ve halen devam eden görüşlerin olduğunu belirtmişler. $\mathrm{Bu}$ durumun hemşireleri bir çok yönden olumsuz etkilediğini, bunun değiştirilmesi için hemşirelere bir görüş kazandırılmayı amaçlamışlardır9. Perfüzyonist mesleğine karşı da kalıplaşmış durumların değişimi ve imajının güçlendirilmesi ve mesleki bilincin artması gerekmektedir.

Çalışmamızda sağlık çalışanlarının büyük bir çoğunluğu perfüzyonistliği bildiklerini ve perfüzyonistin nerede çalıştığını bildiklerini belirtmişler ancak perfüzyonistliğin görev ve yetkilerini ve mesleki niteliğini bilmedikleri görülmüştür. Perfüzyon teknikerliği ile Perfüzyonistliğin aynı meslek olduğunu neredeyse tüm sağlık çalışanları (\%86.4) düşünmektedirler. Ancak perfüzyonistlik ile perfüzyon teknikerliği iki farklı meslektir. Perfüzyonistliğin en az lisans düzeyinde eğitim almayı gerektirdiği, meslek yasasına tabi bir sağlık mesleği olduğu bilinmemektedir. Ayrıca sağlık çalışanlarının perfüzyonistin sadece açık kalp cerrahisi ameliyatlarında rol aldığını düşünmeleri, perfüzyonistin diğer rolleri olan ekstrakorporeal membran oksijenasyon ve ventriküler destek cihazlarında da yetkin ve eğitimli olduklarını bilmediklerini göstermektedir.

\section{SONUÇ}

Perfüzyonistlik mesleğinin gerçek rol ve sorumluluklar1nı, almaları gereken eğitimi sağlık çalışanları halen yeteri kadar bilmemektedir. Hatta bazı sağlık çalışanlarının perfüzyonistliğin meslek olduğunu bilmediği görülmektedir. Çalışmamızda elde ettiğimiz sonuçlara göre:

- Perfüzyonistlerin mesleklerinin gerektirdiği rolleri daha duyarlı bir şekilde yerine getirmeleri, açıklayıcı ve tanıtıcı bilgilendirmeler yapması,

- Perfüzyonistlik mesleğinin topluma ve gençlere etkin bir biçimde tanıtımının yapılması ve üniversitelerdeki perfüzyonistlik okullarının bu tanıtıma öncülük yapmaları,

- Sağlık kurumlarında lise öğrencilerinin meslek seçimine yönelik düzenlenen meslek tanıtım programlarında perfüzyonistlik mesleğine de yer verilmesi,

- Perfüzyonistlerin meslek odalari/dernekleri ve benzeri örgütlerin etkin bir biçimde tanıtım yapması önerilir.

\section{Çıkar çatışması beyanı}

Çıkar çatışması yoktur.

\section{Finansal destek}

Herhangi bir finansal destek kullanılmamıştır. 
J Biotechnol and Strategic Health Res. 2020;4(1):33-38

AMAÇ, BALTACI, Perfüzyonist'in Bilinirliği

Kaynaklar

1. Örer A, Oto Ö. Dünden bugüne kalp cerrahisi, Göğüs ve Kalp Damar Cerrahisi Dergisi. 1999; 7: 1-6

2. 2. Standards and Guidelines for Perfusion Practice. (2017). The American Academy of Cardiovascular Perfusion. https://www.theaacp.com/about/guidelines-of-perfusion-practice/ adresinden 24 Aralık 2019'da erişildi.

3. Task Force on the Expansion of Perfusion Scope of Practice. (2019). American Society of Extracorporeal Technology. http://www.amsect.org/page/scope-of-practice adresinden 29 Aralı 2019'da erişildi.

4. Tababet ve Șabatı San'atlarının Tarzı İcrasına Dair Kanun (2011, 6 Nisan). Resmi Gazete (Sayl: 863). http://www.mevzuat.gov.tr/MevzuatMetin/1.3.1219.pdf adresinden 25 Temmuz 2019'da erișildi.

5. Sağllk Meslek Mensupları İle Sağlık Hizmetlerinde Çalışan Diğer Meslek Mensuplarının Iș ve Görev Tanımlarına Dair Yönetmelik (2014, 22 Mayıs). Resmi Gazete (Sayl: 29007). http://www.mevzuat.gov.tr/Metin.Aspx?MevzuatKod=7.5.19696↔MevzuatIliski=0ゃsourceXmlSearch=SA\%C4\%9ELIK\%20MESLEK adresinden 25 Temmuz 2019'da erişildi.
6. Perfüzyonist kimdir?. (2019). Perfüzyonistler Derneği. http://www.perfuzyon.org.tr/ TR,529/perfuzyonist-kimdir.html adresinden 25 Temmuz 2019'da erişildi.

7. Akçay O. Göğüs cerrahisini taniyor muyuz?. Klinik Tip Bilimleri Dergisi. 2018; 6 (2): 1-4

8. Özdelikara A, Mumcu Boğa N, Çayan N. Hemşirelik öğrencilerine ve sağhlk alanı dışındaki öğrencilere göre hemşirelik imajı. Düzce Üniversitesi Sağlık Bilimleri Enstitüsü Dergisi. 2015; 5 (2): $1-5$

9. Sabancıoğulları, S, Doğan S. Profesyonel kimliğin dıșa yansıyan boyutu: profesyonel imaj ve hemșirelik. Hemșirelikte Eğitim ve Araștırma Dergisi. 2011; 8 (2): 28-37 